\title{
La Doctrina Christiana de Melchor de Vargas, O.S.A.
}

Tras no pocos esfuerzos, he conseguido acceder a la localización y consulta de la Doctrina christiana, escrita por Melchor de Vargas, o con más exactitud, traducida por él al idioma otomí, y que hoy tengo la obligación moral de dar a conocer a todos los interesados en la historia de la catequesis, y más particularmente a los preocupados e inquietos por el tema de la evangelización que se llevó a cabo en tierras americanas.

\section{DESCRIPCIÓN DEL EJEMPLAR.}

El único ejemplar existente en el mundo, lamentablemente mutilado, se encuentra en la Universidad de Austin (Texas), bajo la signatura GZZ-IC70. Dicho ejemplar formó parte de la colección de J. García Icazbalceta, y desde ella pasó a integrar los fondos de la biblioteca que hoy lo conserva.

Se trata de un ejemplar mutilado, que mantiene íntegras -salvo algunos ligeros desperfectos- desde la página $1 \mathrm{r}$ hasta la $23 \mathrm{v}$, y además, la página 27 $\mathrm{r}-\mathrm{v}$ 1. Se trata de un libro en $4^{\circ}$, con paginación únicamente en el recto de las

1. Así lo indica con precisión J. Garcia ICAzbalceta, Bibliografía mexicana del siglo $X V I$, nueva edición por A. Millares Carlo, México, Fondo de Cultura Económica, 19542 revis, 276. En cambio, J. M. SÁNCHEZ, Intento bibliográfico de la Doctrina Cristiana del P. Jerónimo de Ripalda, en "Cultura Española" (1908) oct, 42 señala la carencia de las hojas que seguirían a la página 27, pero omite la pérdida de las páginas 24-26; y R. STREIT, Bibliotheca Missionum, Aachen, Xaverius, II, 325 induce a un error, pues señala únicamente que se trata de un "unvollständiges Exemplar", después de haber señalado la cifra total de 27 páginas, lo que puede hacer creer que la totalidad del ejemplar completo consta de 27 páginas, de las cuales falta alguna en la muestra presente. 
hojas ${ }^{2}$; además figuran signaturas que son A-B6 ${ }^{3}$ (que abarcarían hasta la página 24, hoy inexistente), mientras que en la página 27 , no se aprecia la signatura, por estar deteriorada la parte inferior en el lugar correspondiente a la signatura. Con arreglo al cálculo que se verá más adelante, estimo que el cuadernillo correspondiente a la signatura $\mathrm{C}$ (del que forma parte la página 27) tendría que ser $\mathrm{C} 4$, pero esto es sólo una estimación, pues aunque la página 27 hubiera conservado la signatura, ésta hubiera sido "C iij", y no hubiera sido posible conocer con exactitud la extensión del cuadernillo, que es, con toda seguridad, el último.

El libro combina diversos tipos de letras: letra gótica para la portada; cursiva para la epístola nuncupatoria (f. 1v); gótica para la cartilla (f. 2r), y redonda para la orden ejecutoria (f. 2 r); el resto se distribuye en tres bloques (pues el texto es trilingüe): el vuelto de las hojas, a toda plana, en letra gótica para el texto náhuatl, y el recto, a dos columnas, contiene en la de la izquierda el texto castellano en letra redonda, y el texto otomí en gótica.

Los títulos de las páginas, en letra cursiva, rezan "Doctrina christiana Mexicana" en los f. vueltos (desde el f. $2 \mathrm{v}$ ), y se continúan en los títulos de los f. rectos (desde el f. 3r) con "Castellana y Otomí". Los textos de la doctrina en cualquiera de los tres idiomas carecen de reclamos. Dispone de numerosos grabados, de los que me ocuparé más adelante. En el libro aparecen una serie de anotaciones manuscritas, evidentemente posteriores, de las que simplemente me limito a dejar constancia. En la portada, a la altura del título figura, a la izquierda la anotación "S. agostí", y a la derecha, casi a la misma altura, pero sin que se pueda establecer necesariamente conexión entre ambas, se lee "patre"; en la misma portada, al pie del título (dispuesto escalonadamente, como solía ser frecuente con los colofones, se lee "años" a la izquierda, mientras que a la derecha hay una anotación de difícil lectura, cuya transcripción podría ser "AteAz" (?). Otra nota manuscrita aparece en f.14v que reza "Tlaxiquito in Salve", justo debajo del correspondiente texto náhuatl impreso, como ejercicio de copia de algún usuario del catecismo. Algo semejante ocurre en f. 16v, pues en la parte inferior de la hoja se lee "Dios. Ymneltococa": la segunda palabra es copia de la que en el texto impreso figura ocho líneas más arriba, al comienzo de los artículos fe en

2. Carecen de paginación la hoja 1r (portada), la hoja $2 \mathrm{r}$ (que incluye el alfabeto al comienzo de la página), la hoja $12 \mathrm{r}$ (por desperfecto en la parte superior; la hoja $22 \mathrm{r}$ contiene un error de paginación, pues en realidad figura " 20 ".

3. Igual que ocurría con la paginación, hay un error en la signatura, pues en la página 18 debería corresponder la signatura "B vj", en tanto que en el escrito figura "A vj", cuando es evidente que se integra en el segundo cuadernillo. 
náhuatl. En f. 18v, casi en la parte superior figura otra inscripción "Ha...anima....su Hijo". Finalmente, el f. 23v incluye otra anotación ilegible en la parte inferior.

En las páginas que se han conservado de la obra, figuran algunos leves desperfectos que son los siguientes: página 12 ( $\mathrm{r}-\mathrm{v}$ ) hay dos rotos, uno que afecta a la parte superior de la página, que no afecta al texto, y otro un poco más abajo que afecta al texto dé la columna de otomí en f. 12r, y a un grabado en f. 12v. En f. 23 (r-v) hay una amplia desgarradurra que afecta a la parte inferior externa de la hoja, haciendo desaparecer media columna del texto otomí en el recto de la hoja y una ligera parte del texto náhuatl, así como la mitad de uno de los grabados en la vuelta de la hoja. La página 27 aparece cortada en la parte inferior, afectando quizá a una línea del texto otomí.

\section{CONTENIDO DE LA OBRA.}

Aun tronco, el ejemplar posee los suficientes datos para desvelar algo de su historia, ya que no se pueda reconstruir ésta en su integridad. El análisis del contenido de este catecismo nos va entregando, a regañadientes, algunos retazos de lo que con certeza en unos casos, y tan sólo en hipótesis en otros se puede llegar a saber de él, con los problemas que aún subsisten y que sólo he conseguido resolver en parte. De ahí que haya que pasar al análisis del contenido de la obrá.

Como solía ser frecuente, el título, largo, aporta una información sucinta sobre la historia del catecismo: Doctrina Christiana, muy vtil, y | necessaria en Castellano, Mexicano y Otomí: tradu- Izida en lengua Otomí por el muy. R. padre Fray | Melchior de Vargas, de la orden de sant Augu I stin, Prior de Atocpan. ordenada por man $\mid$ dado del yllustrissimo y Reuerendis- I simo señor Don Pedro Moya de | Contreras, Arçobispo de ! México, del consejo de | su Magestad: y con | licencia im- I pressa. I (Grabado de San Agustín) I CON PRIVILEGIO I En Mexico, en casa de Pedro Balli. Año de 1576. El no disponer de colofón hace que verosímilmente, alguna de las informaciones que suelen encerrarse en ellos, se haya perdido definitivamente para reconstruir los pasos de la historia de este catecismo.

El f. 1v , entero, contiene la epístola nuncupatoria que Melchor de Vargas Dirige al arzobispo de México, Pedro Moya de Contreras, cuyo texto íntegro es: "Es la obediencia de tanta virtud y fuerça, illustrissimo Señor, que haze aun a las cosas que no tienen algun principio ni rayz para crecer, ser fertiles y fructificar, como aura $V$. Señoria yllustrissima visto, en las vidas de los 
Padres. Que fue de tanta efficacia la obediencia de un monge, a quien su Perlado mando plantar una vara seca sin rayz y sin virtud: y obedeciendole, regandola y cultiuandola, hizo con el fabor diuino que brotasse y diesse fructo. esso mesmo he sentido de mi siervo sin prouecho e inutil, mas confio en la Magestad diuina, que por subjetarme a la obediencia de V. Señoria, que me mando interpretar esta Doctrina Christiana en lengua Otomi, haziendo lo que es en mi, aßi en esta como en las demas obras que muy presto saldran a luz como a $V$. Señoria consta, sea mucho de seruir nuestro Señor y hazerse gran prouecho en las almas: en el entretanto que lo demas se examina, puede $V$. Señoria mandar se imprima esta que, aunque breue, es provechosa y va la lengua Otomi muy propia y clara: y sera vn principio para que con mas animo, (cognosciendo ya no ser tan espantable lengua como se pinta.) Accepten lo futuro, confio en la bondad de Dios, que despues de seguirse su seruicio, y bien comun de las almas no perdera el merito vuestra señoria yllustrißima, cuyo feliz estado prospere nuestro Señor muchos años. De atocpan, veinte y dos de Agosto de M.D.LXXVI. Yllustrissimo Señor.Besa las manos a vuestra Señoria yllustrissima Su obediente e yndigno Capellan Fray Melchior de Vargas".

El f. 2r está ocupado en su mayor parte por la cartilla y los consiguientes ejercicios de silabeo. En primer lugar aparece completo el alfabeto, más algunos de los signos de abreviaturas usuales en la tipografía del XVI. A ello sigue una indicación: "Abc para la lengua Otomí"; aunque parezca que tal sugerencia es ociosa y se limita a repetir el alfabeto con letras de cuerpo más pequeño, esto no es así, ya que introduce algunas variaciones que posteriormente van a aparecer a lo largo del texto de la doctrina cristiana en otomí. Estas variaciones son: - después de la "c", incluye la "ch" como letra independiente; - después de la "d", incluye un signo similiar a una combinación de "d" larga y "l"; - después de la "e" incluye también otro signo que consiste en una "e" precedida de otro rasgo gráfico desconocido: - la "f" figura como "ph" (cosa que no sucede en el alfabeto castellano que ha presentado en la misma página); - elimina la "l", la " $r$ " y la "s"; - después de la " $t$ ", incluye como otra letra la doble "t": "tt" y, además, "th"; - después de la "y" incluye "tz", "z" y "tzh". A la vista de semejantes variaciones, se aprecia que la labor de alfabetización y sistematización de la lengua otomí ha tenido que partir de los datos básicos del análisis de los sonidos y la adscripción de la correspondiente equivalencia gráfica, llegando en algunos casos a crearla, aunque hubiera que superar la ausencia de signo correspondiente en la lengua castellana.

Terminada la parte del alfabeto otomí, siguen las propuestas de ejercicios de silabeo, destinadas, como es notorio, al empleo de la lengua otomí, 
ya que aparecen algunas particularidades que no constan en la lengua castellana, ni tampoco en la náhuatl. Estas se pueden concretar en las siguientes: a todas las sílabas en que combina las consonantes con las vocales, sigue un segundo ejercicio en que combina las mismas consonantes con las vocales pero todas marcadas con acento circunflejo, expresando a las claras otro matiz en el sonido de la vocal que no incluía en la primera representación gráfica; además, a continuación de esta segunda grafía con acento circunflejo, añade otra nueva vocal que concreta en la grafía "œ”, de manera que el conjunto de sílabas que propone para cada vocal son: "ba, be, bi, bo, bu, bâ, bê, bî, bô, bû, bœ". A continuación de los ejercicios de silabeo, incluye una nota,cuyo texto es: "Los auisos para saber leer la lengua Otomí, van a la postre en la vltima hoja deste libro".

La parte inferior de este f. $2 \mathrm{r}$ incluye la orden ejecutoria del arzobispo Pedro Moya, redactada en los términos siguientes: Manda su Señoria yllustrissima a todos los Curas y Vicarios deste Arçobispado que so pena de diez pesos de minas tengan y enseñen en esta Doctrina christiana a sus subditos $y$ se la hagan tomar y enseñar para que sean instruydos en las cosas de la Fe, como en ella se contiene, y que no enseñan por otra, porque no aya confusion. $Y$ ruega y encarga a todos los Perlados, assi Obispos como religiosos, assi mesmo hagan enseñar a los Indios por ella.

A partir del f. $2 \mathrm{v}$, discurre la doctrina cristiana, tal como he descrito anteriormente: las páginas vueltas, contienen, a toda plana, salpicada de grabados, con letra de cuerpo mayor, porque dispone de más espacio, el texto náhuatl. A lo largo de escrito náhuatl, en diversos momentos se interrumpe la presentación para incluir títulos, en una o dos líneas, que van señalando las diversas materias de que se está tratando. En las páginas rectas, a dos columnas, con letras de cuerpo menor (redonda para el castellano y gótica para el otomí) se va presentando en paralelo el texto de la doctrina en ambos idiomas. Dado que el texto castellano es más conciso que el otomí, y que precisa menor espacio, también la columna correspondiente al castellano está jalonada de grabados, en tanto que la columna reservada para la doctrina en otomí no dispone de uno solo; otro tanto sucede con los títulos que señalan las diversas partes que se van abordando, que en el caso de la columna castellana se distinguen con nitidez, introduciendo la presentación de los diversos apartados, mientras que en el texto otomí, o no existen, o hay que buscarlos, porque ni se resaltan ni se utiliza letra de cuerpo mayor para dejar constancia del paso de un tratado al siguiente, ya que se precisa todo el espacio disponible. 


\section{GRABADOS.}

El texto está ampliamente adornado de grabados, cuya ubicación, por razón del espacio disponible en las lenguas respectivas, es indefectiblemente en las páginas correspondientes al náhuatl y en las columnas del texto castellano, no así en el texto otomí. Hay un total de 70 grabados, de los cuales 50 no están repetidos, y sólo 20 aparecen dos o tres veces; ello da al libro una notable agilidad tipográfica, aunque haya que tener en cuenta que en algunas páginas se acumula más de uno, mientras que hay cinco páginas que no tienen ninguno.

Los grabados no proceden todos de la misma mano, ni siquiera de la misma colección ni tamaño, aunque aproximadamente resulten similares (salvado el más grande de la portada). Se percibe que integran varias "colecciones" de las que han sido tomados para ilustrar este catecismo. Algunas de esas series hacen referencia a la vida de Jesús, a los sacramentos, a alegorías de los evangelistas, o alegorías de las virtudes, etc... El impresor Pedro Balli, como solían hacer todos los impresores, utiliza lo que tiene a mano, acompasándolo, en la medida de lo posible con el discurrir del texto y la explicación correspondiente. Ni siquiera he intentado hacer una comparación con grabados que figuran en otros catecismos impresos en México, aunque hay que dejar constancia de que algunos de esos grabados se repiten y han ido pasando de un impresor a otro o de un taller a otro, por sucesión, compra, alquiler, préstamo,... pues aparecen en catecismos impresos en una u otra de las tipografías establecidas en tierras mexicanas.

La descripción sistematizada de los grabados es la que sigue, teniendo en cuenta las indicaciones anejas de la columna paralela: la referencia precedida de > remite a lugares en que se repetirá más adelante el mismo grabado; mientras que la referencia con + remite a lugares en que el mismo grabado ha aparecido con anterioridad:

$\begin{array}{lll}\text { 1r } & \text { S. Agustín } & \\ 1 \mathrm{v} & \begin{array}{l}\text { Capital: vasallo ante su reina } \\ 2 \mathrm{v}\end{array} & \begin{array}{l}\text { 1) Niño Jesús bendiciendo. Leyenda: } \\ \text { Ego et veritas }\end{array} \\ & \begin{array}{l}\text { 2) Alegoría S. Mateo } \\ \text { 2) }\end{array} & >5 \mathrm{v}, 2: \text { réplica }) \\ 3 \mathrm{r} & \begin{array}{l}\text { Franciscano con personas. Leyenda: } \\ \text { Ichuca Dioseuri bandaqua }\end{array} & >27 \mathrm{r} \\ 3 \mathrm{v} & \begin{array}{l}\text { 1) Doctor en su cátedra } \\ \text { 2) Calvario }\end{array} & >7 \mathrm{v} ; 20 \mathrm{v}, 1\end{array}$


$4 \mathrm{r}$

1) ¿Santo? con cartelas sin leyenda

2) Trinidad

$4 \mathrm{v}$

1) Alegoría S.Juan evangelista

2) Calvario (distinto de $3 v, 2$ )

$5 \mathrm{r}$

1) Santo arrodillado ante crucifijo

2) Santo obispo (¿S. Agustín?)

$5 v$

6r

7v

$8 r$

9r

9v

$10 \mathrm{r}$

1) Anunciación

2) Jesús consolado por un ángel

11r 1) Coronación de María 2)Jesús consolado por un ángel

11v 1) Franciscano entre niños

2) Coronación María (distinta de 11r,1)

$12 r$ 1) Santo con cartelas sin leyenda

2) Escena de vida de Job

$12 \mathrm{v}$

1) Virgen orlada de rosario (roto)

2) Coronación Virgen

(distinto de 11r,1 y 11v,2)

13r Trinidad

13v 1) Calvario

2) Escena vida de Jesús

14r Flagelación

14v Exaltación/coronación María

15v Coronación María

15v 1) María con el Niño

2) Alegoría: IHS: In hoc nomine oportet nos salvos fieri

16r Predicación de Jesús sobre el sembrador

$16 \mathrm{v}$ 1) Pentecostés

2) Escena vida Job

17r. Trinidad

$17 \mathrm{v}$ 1) Persona orando de rodillas
$>13 \mathrm{v}, 1$

$>6 \mathrm{r}, 1$

$$
\begin{aligned}
& +2 \mathrm{v}, 2 \\
& +4 \mathrm{v}, 2 \\
& +4 \mathrm{r}, 1 \\
& +3 \mathrm{v}, 1:>20 \mathrm{v}, 1 \\
& +4 \mathrm{r}, 2
\end{aligned}
$$

$$
>13 \mathrm{r}
$$$$
>12 r, 1
$$

$>11 \mathrm{r}, 2$

$>15 \mathrm{r}$

$+10 \mathrm{v}, 2$

$+10 \mathrm{r}, 1$

$>16 \mathrm{v}, 2$

$>21 \mathrm{v}, 1$

$+10 \mathrm{r}, 1$

$+3 \mathrm{v}, 2$

$+11 \mathrm{r}, 1$

$>19 \mathrm{v}, 1 ;>27 \mathrm{v}, 1$

$+12 \mathrm{r}, 2$

$+4 \mathrm{r}, 2$ 
2) Nacimiento

18r ¿Escena de un religioso con Jesús?

$18 \mathrm{v}$ 1) Coronación de espinas

2) Ascensión

19r Jesús cargado con la cruz

19v 1) Pentecostés

2) Alegoría S. Marcos

20r Obispo confirmando

20v 1) Doctor en su cátedra

2) Busto de Jesús: Ego sum panis vivus qui de coelo descendi Io.6

21v

1) Coronación María

2) Niño Jesús bendiciendo: Ego sun via et veritas

$22 \mathrm{r}$ ¿Resurrección de muertos?

22v 1) Circuncisión Jesús

2) Nacimiento

$23 r$

Unción enfermos

$23 \mathrm{v}$ 1) Alegoría virtud ¿justicia?

2) Alegoría virtud ¿fe?

3) Jesús con otro personaje (incompleto)

$27 \mathrm{r}$

Franciscano con personas

$27 v$ 1) Pentencostés

2) Circuncisión
$>22 \mathrm{v}, 2$

$+16 \mathrm{v}, 1 ;>27 \mathrm{v}, 1$

$+3 \mathrm{v}, 1 ;+7 \mathrm{v}$

$+12 \mathrm{v}, 2$

(réplica de $2 \mathrm{v}, 1$ )

$>27 \mathrm{v}, 2$

$+17 \mathrm{v}, 2$

$+3 \mathrm{r}$

$+16 \mathrm{v}, 1$

$22 \mathrm{v}, 1$

El conjunto de los grabados presta al catecismo una notable elegancia, de la que no siempre estaban provistos los catecismos impresos en Europa. Pero además de la elegancia, tenía obviamente la función de ir presentando con el lenguaje de la intuición aquellos aspectos que a su vez se iban ofreciendo en el texto indígena respectivo (náhuatl u otomí) ${ }^{4}$, reforzando de esta manera lo que estaba escrito con la elocuencia del grabado; de ahí, que aun contando con la limitación temática (repeticiones, escasez), así como la

4. Del grabado del franciscano entre varias personas, con una leyenda, afirma J. GARCíA ICAZBAlceta, Bibliografía mexicana del siglo XVI, nueva edición de A. Millares Carlo, México, Fondo de Cultura Económica, 1954" revis., 80-81: "La leyenda que sale de la boca del fraile dice: Ichura Dioseuri bandaqua, que son palabras de lengua tarasca y significan Esta es la palabra de Dios. Llama la atención que la leyenda esté en tarasco: lo primero, porque prueba que el escudito (no de los peores de la época) fue grabado aquí, y no traído de España con los demás útiles de imprenta; lo segundo, porque es racional pensar que se hizo para alguna obra en ese idioma...". A pesar de ello, se emplea, como vemos en este catecismo, además de otros, que nada tienen que ver con el tarasco. 
de tamaño, los grabados servían para que lo explicado o leído penetrara más directamente por los ojos, y quedara plasmado en la retentiva de los indios.

\section{AUTORIA.}

Al abordar semejante cuestión no hay más remedio que partir de dos datos insoslayables: la ausencia real de nombre de autor; y la identidad total con otro catecismo de la misma época.

- Ausencia de nombre de autor. Efectivamente, el título precisa con meridiana claridad que la Doctrina Christiana ha sido "traduzida en lengua otomí por el muy R. padre Fray Melchior de Vargas"; asimismo, la epístola nuncupatoria vuelve a insistir en el mismo punto, sin que aporte dato nuevo al respecto: "V. Señoría me mandó interpretar esta Doctrina Christiana en lengua Otomí...". De lo cual no se puede decir otra cosa más que la intervención de Melchor de Vargas en lo relativo a la versión otomí de un catecismo preexistente que se le ordena traducir.

$\mathrm{El}$ otro nombre propio que figura igualmente en el título (“...Ordenada por mandado del yllustrissimo y Reuerendissimo señor Don Pedro Moya de Contreras, Arçobispo de Mexico...”), y en la epístola nuncupatoria (Al Illustrissimo y Reverendissimo S. Don Pedro Moya de Contreras, Arçobispo de México...") tampoco puede ser entendido como el del autor, pues se limita a ordenar la ejecución de la doctrina, o simplemente la traducción, o bien ambas cosas, pero en modo alguno se puede afirmar que se trata de un catecismo escrito por él.

Hay que llegar a la conclusión de que al menos materialmente hablando, la obra resulta anónima, al no figurar directamente nombre de autor alguno a quien asignársela. Si únicamente hubiera que tener en cuenta este primer aserto, la ausencia de nombre de autor no permitiría ir más lejos. Es preciso complementarlo con el segundo dato.

- Identidad con otro catecismo. Al comprobar el contenido del texto, es obligado compararlo con otro catecismo que circulaba por México por los mismos años. Se trata de la Doctrina Christiana muy util, y | necessaria, assi para los Españoles, como para los natu I rales, en lengua Mexicana y Castellana, ordenada por mandado del Illustrissimo y Reuerendissimo I Señor Don Pedro Moya de Contreras I Arçobispo de Mexico, del consejo de su | Magestad, y con su licen- I cia impressa. La obra ha sido impresa en la tipografía de Pedro Balli en 1578. Igual que ocurre con el texto anterior, aparece materialmente anónima, pues la alusión a Pedro Moya no se ha de entender como 
que éste sea su autor. Dicha obra, recientemente publicada en edición facsímil, la he atribuído, por una serie de razones al franciscano Francisco de Pareja 5 .

Efectuado el cotejo del contenido de ambos catecismos (al menos en lo que hace al texto castellano y náhuatl), se puede comprobar que contienen la misma doctrina, sin otras variaciones que las ligerísimas que anotaré más adelante, y que no suponen más que leves rectificaciones, de manera que hay que asegurar que se trata del mismo y único catecismo, si bien con las modificaciones pertinentes que hacen de él la base de dos versiones diversas.

Además de la identidad prácticamente absoluta del texto, existen otra serie de semejanzas que no puedo por menos de resaltar. En primer lugar, la cuestión del título respectivo:

CATECISMO DE 1576.

Traductor MElChOR DE VARGas.
CATECISMO DE 1578.

Autor Francisco de PAREJA.
Doctrina Christiana, muy vtil, y I necessaria en Castellano, Mexicano y Otomí: tradu- Izida en lengua Otomí por el muy. R. padre Fray | Melchior de Vargas, de la orden de sant Augu I stin, Prior de Atocpan. ordenada por man I dado del yllustrissimo y Reuerendis- I simo señor Don Pedro Moya de I Contreras, Arçobispo de 1 México, del consejo de I su Magestad: y con | licencia im- I pressa. I (Grabado de San Agustín) I CON PRIVILEGIo | En Mexico, en casa de Pedro Balli. Año de 1576.
Doctrina Christiana muy util, y necessaria, assi para los Españoles, como para los natu I rales, en lengua Mexicana y Castellana, ordenada por mandado del Illustrissimo y Reuerendissimo I Señor Don Pedro Moya de Contreras $\mid$ Arçobispo de Mexico, del consejo de su | Magestad, y con su licen- I cia impressa | (Grabado) । CON PRIVILEGIO | En Mexico En casa de Pedro Balli. | Esta tassado en dos Reales, y medio.

Se puede observar un evidente paralelismo en lo substancial del título, que aporta los mismos datos fundamentales como es el título de Doctrina christiana muy util y necesaria, así como que en ambos casos esté ordenada por mandado del Illustrissimo y Reuerendissimo señor Don Pedro Moya de

5. L. Resines, Francisco de Pareja. Doctrina cristiana muy útil y necesaria. México, 1578, Salamanca, Servicio de Publicaciones de la Universidad, 1990. La cuestión de la autoría ocupa las páginas 23-36. 
Contreras. Las divergencias estriban en los tres idiomas de la doctrina de 1576 (con la adición del encargado de la traducción), así como en el hecho de que mientras la doctrina de 1576 es simplemente muy util y necessaria, la doctrina de 1578 especifica que es muy util y necessaria assí para los Españoles como para los naturales.

No es la única similitud existente entre ambos catecismos, pues aparece otra en la orden ejecutoria promulgada por el arzobispo de México, Pedro Moya, que puesta en paralelismo es así:

CATECISMO DE 1576.

TRADUCTOR MELCHOR DE VARGAS.
Catecismo de 1578.

Autor Francisco DE PAREJA.
Manda su Señoria yllustrissima a todos los Curas y Vicarios deste Arçobispado que so pena de diez pesos de minas tengan y enseñen en esta Doctrina christiana a sus subditos y se la hagan tomar y enseñar para que sean instruydos en las cosas de la Fe, como en ella se contiene, y que no enseñan por otra, porque no aya confusion. $Y$ ruega y encarga a todos los Perlados, assi Obispos como religiosos, assi mesmo hagan enseñar a los Indios por ella.
Aquel que es muy ilustre señor espiritual don Pedro Moya de Contreras, Arzobispo aqui en la ciudad de México, ordena a todos los prelados, curas y vicarios, e igualmente a todos los fiscales, que están encargados de enseñar a los niños pequeños y a los ancianos, tanto españoles como gente de la tierra, que les enseñen (mediante) esta Doctrina Christiana, como está en el Santo Concilio, a propósito de lo que se enseñará en el templo. $Y$ quienes así no lo hagan serán castigados como está ordenado. Año 1578.

(Colofón)

Las semejanzas entre ambas requisitorias radican en la obligatoriedad que se impone de que se utilice el texto de la doctrina como texto único y excluyente, haciendo extensiva dicha obligación a los prelados y religiosos, a fin de conseguir la uniformidad en la enseñanza del catecismo. Las divergencias señalan en el primer caso una pena pecuniaria ("diez pesos de minas"), que en el segundo caso no figuran más que genéricamente ("serán castigados"); en cambio el catecismo de 1578 alude expresamente a la autoridad del "Santo Concilio", a la que no se recurre en el caso del catecismo de 1576.

Además de hablar de las semejanzas, es preciso subrayar las diferencias no sólo en el título, sino en el resto del catecismo. Se aprecian ligeras varian- 
tes de escasa importancia como es el caso de modificar "lagrimas" de la Doctrina de 1576, por "lagrymas" en la de 1578, pero substancialmente el texto es el mismo, aunque compuesto de nuevo; hay divergencias de una letra mayúscula que ha pasado a minúscula, hay palabras en la Doctrina de 1576 que figuran completas ("nuestros") y en la de 1578 aparecen en abreviatura ("ntros"). Tampoco hay coincidencia completa en la cantidad de materia que entra en la columna en castellano de las dos Doctrinas. Los grabados son diversos en cantidad y distribución, pues aunque algunos se repiten, en la Doctrina de 1576 aparecen grabados en las páginas de náhuatl, y en la columna de castellano, mientras que en la Doctrina de 1578 no aparecen más que grabados en la columna de castellano.

Además, hay tres variantes reseñables por su cierta importancia: 1) en la Doctrina de 1576 se dice al final del avemaría: "...pecadores ahora y en la hora de la muerte. Amen" (f. 11r), mientras que en la Doctrina de 1578 se dice en el mismo lugar: “...pecadores. Amén (f.5v). 2) A propósito de la Trinidad la Doctrina de 1576 dice: "y assi lo veremos en el Cielo claramente" (f. $10 \mathrm{v}$ ), en tanto que la Doctrina de 1578 altera el orden: "y assi lo veremos claramente en el Cielo". 3) Con relación a las virtudes, la Doctrina de 1576 propone: "Pregunta. Quales son? Respuesta. Fe, esperança y Charidad" (f. 23r), mientras que por su parte la Doctrina de 1578 introduce una serie de modificaciones: "Pre. Quales son? Resp. Tres virtudes Theologales. Fee. Esperança y Charidad" (f. 11v).

Una de las razones en que me apoyaba para atribuir la autoría del catecismo de 1578 a Francisco de Pareja era la similitud en el título de ese cate.cismo con otro publicado por él en 1612, a su regreso de la estancia en La Florida 6 . Creo que la aparición de este otro catecismo, cuyo título ya era conocido, y que incluí en el estudio anteriormente citado no altera para nada la razón de esta atribución, puesto que si, en verdad, el autor del catecismo es Francisco de Pareja, éste pudo perfectamente señalar el título que estimó más conveniente, y que se altera en el catecismo de 1576, para introducir la modificación de la traducción de Melchor de Vargas, así como el número de lenguas de que consta tal ejemplar. Cuando posteriormente publicó el cate-

6. Este catecismo lleva por título: Cathecismo y Breve Exposición de la Doctrina Christiana. Muy útil y necessaria, assí para los Españoles como para los naturales, en Lengua Castellana y Timuquana, en modo de preguntas, y respuestas. Compuesto por el P. Fr. Francisco Pareja, de la Orden de N. Seraphico P. S. Francisco, Padre de la Custodia de S. Elena de la Florida. Con licencia de los Superiores, en casa de la viuda de Pedro Balli. Año de 1612. Por C. A. César. Es evidente el parecido en el título con el catecismo de 1578, publicado, en la misma imprenta, cuando aún era llevada por Pedro Balli, y no por su viuda como ocurre unos años más tarde, a la hora de la edición del catecismo de 1612. 
cismo en castellano y timuquano siguió empleando en la práctica el mismo título, con alguna ligera modificación.

Pero cuando publiqué la edición facsímil del catecismo de 1578 atribuído a Francisco de Pareja, no había llegado a mis manos la copia del catecismo de 1576, por lo cual, hube de arriesgar una serie de preguntas como hipótesis de trabajo. Dichas preguntas eran: “¿Se contiene en ambas [las doctrinas de 1576 y 1578] un texto 'oficioso' del I Concilio Mexicano? ¿Se trata de un texto posterior, que podríamos denominar 'privado', y que Pedro Moya estima razonablemente válido para satisfacer con él las prescripciones del Concilio, como había hecho Alonso de Montúfar con la Doctrina de Domingo de la Anunciación 7? Además hay que preguntarse en qué pudo consistir la orden de Pedro Moya: en el caso de la Doctrina de 1576 consta expresamente que 'V. Señoría me mandó interpretar esta Doctrina en lengua Otomí'. Hay que rechazar que la orden de Pedro Moya respecto a la Doctrina de 1578 consista en la versión al náhuatl, puesto que la de 1576 de Melchor de Vargas es trilingüe (castellano-náhuatl-otomí): carece de lógica ordenar que se ejecute lo que ya está hecho y publicado. ¿Hay que atribuir también ésta de 1578 a Melchor de Vargas, o es más adecuado pensar que Pedro Moya ha ordenado a alguien que la ponga en náhuatl, y a Vargas exclusivamente la versión otomí, de la que éste se siente responsable?" 8.

La disponibilidad de nuevos datos puede arrojar luz a toda este serie de interrogantes, que, parcialmente, al menos, había tratado de responder en la publicación aludida.

En primer lugar, respecto al carácter jurídico del texto, de ninguna manera se trata de un texto oficial, elaborado por decisión del I Concilio ProvincialıMexicano de 1555: no se llevó a cabo un catecismo que gozase de dicho carácter. Y de la misma manera que Alonso de Montúfar otorgó la categoría de "oficioso" al catecismo de Domingo de la Anunciación, Pedro Moya de Contreras hizo lo propio con este otro texto de catecismo en su doble versión trilingüe de 1576 y bilingüe de 1578. Es por tanto, un texto

7. En la carta dedicatoria de Domingo de la Anunciación a Alonso de Montúfar, le dice: "...Me mandó [V.S.R.] que yo tomase a cargo de componer o recopilar una breve Doctrina Cristiana y otra más copiosa... para que entre ambas se sacasen en todas las lenguas que fuese posible desta Nueva España y se imprimiesen según lo ordenado en el sacro Concilio Mexicano por V.S.R. y por los señores Obispos que en él se hallaron..." (Reproducción de J. Salvador y Conde, El Padre Domingo de la Anunciación y su personalidad misionera, Madrid, Ed. Jura, 1950, 78. Ese "mandato" de Alonso de Montúfar hay que interpretarlo más en el sentido de que se trata de un texto que reune los requisitos pergeñados en el I Concilio Provincial, y que, aún sin la categoría de texto oficial, puede darse por bueno en cuanto a la ejecución de las intenciones del Concilio.

8. L. RESINES, o.c., 26. 
“privado", pero dotado de una relevancia singular, y que Pedro Moya propone y en cierto modo exige que se utilice como texto único en toda la demarcación de su arzobispado. Sin embargo, tal deseo de convenir en la unidad de un sólo texto de catecismo no pasa de ser la expresión de un propósito que no se lleva a cabo, ya que los hechos desmienten clamorosamente las intenciones 9. Quedan así respondidas las dos primeras preguntas.

En segundo lugar, acerca de en qué consiste la orden o mandato de Pedro Moya, resulta difícil ser absolutamente precisos. También la Doctrina de Domingo de la Anunciación, había sido "ordenada" por Alonso de Montúfar, y no hay que entender más que se trata de una aprobación o beneplácito de un texto que estima aceptable para cumplir los propósito del I Concilio Provincial Mexicano. Aplicando este mismo criterio, las Doctrinas de 1576 y 1578 han sido "ordenadas" por Pedro Moya, es decir, han sido aceptadas o aprobadas por él (o acaso hay que matizar más aún, afirmado en singular "aceptada o aprobada", puesto que se trata de la misma Doctrina).

Pero hay que tener presente que Melchor de Vargas se siente responsable únicamente de la versión otomí ("traduzida en lengua otomí por...", dice la portada; y "...que por subjectarme a la obediencia de V. Señoría, que me mandó interpretar esta Doctrina Christiana en lengua Otomí...", dice la carta dedicatoria). Las frases citadas "podrían dar la impresión de que la obra de Melchor de Vargas responde a una decisión preexistente de Pedro Moya, pero, al contrario, la afirmación también contenida en el prólogo de que 'puede V. Señoría mandar se imprima ésta' más bien parece una solicitud, que la ejecución de una orden anterior: carece de lógica -incluso como frase protocolaria y reverencial- el demandar el cumplimiento de sus propias decisiones. Por lo cual es forzoso concluir que la frase 'ordenada por manda$d o$ ' (o ' $V$. Señoría me mandó interpretar') bien puede ser entendida en el sentido de que Pedro Moya apruebe y ratifique el trabajo que se le presenta" 10:

9. En la década de 1570-1580, se publicaron los siguientes catecismos: JUAN DE LA CRUZ, Doctrina cristiana en lengua guasteca..., México, Pedro Ocharte, 1571; DIEGo DE LANDA, Doctrina cristiana traducida en la lengua de los indios de Yucatán, ejemplar no localizado, 1574; JuAn de Medina, Doctrinalis fidei in mechoacanensium indorum lingua... Tomus secundus., Mexici, Antonio de Espinosa, 1575; JuAn de la Anunciacion, Doctrina christiana muy cumplida..., México, Pedro Balli, 1575; MATURIno Grlberti, Tesoro spiritual de pobres..., México, Antonio de Espinosa, 1575; JUAN DE LA ANUNCIACION, Catecismo en lengua Mexicana y Española..., México, Antonio Ricardo, 1577; JuAn de Medina, Doctrinalis fidei in Mechoacanensium indorum lingua... Tomus primus., Mexici, Antonio Ricardo, 1577; Alonso DE Molina, Doctrina christiana en lengua mexicana..., México, Pedro Ocharte, 1578; SANcho Sanchez De Muñon, Doctrina cristiana, México, ¿Antonio Ricardo?, 1579. A esta larga lista, habría que añadir, como impresos, el de 1576, traducido por MELCHOR DE VARgas, y el de 1578, atribuido a Francisco de Pareja. Además, sería preciso tener en 
el mandato $\mathrm{u}$ orden de Pedro Moya se concreta en el caso de la Doctrina de 1576 de Melchor de Vargas en que éste traduzca al otomí el texto castellanonáhuatl escrito por Francisco de Pareja.

Hay una duda, más que evidente, que es preciso contestar. ¿Cómo es posible que Pedro Moya ordene a Melchor de Vargas traducir al otomí para que se publique en 1576, el catecismo que Francisco de Pareja escribe en 1578 , también por orden del mismo Pedro Moya?

Si no existieran más ejemplares que la Doctrina de 1576, traducida por Vargas, y la Doctrina de 1578, cuya autoría he atribuído a Pareja, no habría más remedio que aventurar la suposición de que en realidad la Doctrina de 1578 no fuera la primera edición (pese a que el texto nada aporta en el sentido de "nuevamente impresa", o frase similar). Pero al publicar el facsímil de la edición de 1578 , dejé constancia de que existía un ejemplar fragmentario, conocido por la magnífica descripción de Icazbalceta ${ }^{11}$. En ese momento llegué a las siguientes conclusiones: " $1^{\circ}$ se trata de la misma obra; $2^{\circ}$ pero ejemplares distintos, correspondientes a ediciones distintas; $3^{\circ}$ como el presente ejemplar [el fechado en 1578] está completo y para nada aparece el tan usual 'ahora nuevamente impresa', no es demasiado difícil suponer que el ejemplar fragmentario consultado y descrito por Icazbalceta pertenece a una edición posterior" 12.

Pero afortunadamente la consulta de ese ejemplar fragmentario descrito por Icazbalceta ${ }^{13}$ arroja nueva luz sobre el tema. A este ejemplar incomple-

cuenta también el de BERNARdINo DE SAHAGUN, Doctrina christiana mexicana, ¿1579? y el de DiEgo de CARRAnZA, Doctrina cristiana en lengua chontal, a datar entre 1577 y 1590.

Como se puede ver, la pretendida unidad de texto de catecismo no dejaba de ser un ideal muy lejano de alcanzar, pues en fechas inmediatamente anteriores y posteriores a las que centran este estudio, se publican una serie abundante y variada de catecismos, sin tener en cuenta para nada la unidad, que únicamente está conservada por estos dos ejemplares, que en realidad, como ya he indicado, no constituyen más que uno.

10. L. Resines, Catecismos americanos de religiosos agustinos en el siglo XVI, en VARIos, Agustinos en América y Filipinas. Actas del Congreso Internacional, ValladolidMadrid, 1990, 520-521.

11. En la primera edición de J. Garcia ICAzbalceta, Bibliografía mexicana del siglo XVI, México 1886, 392-393, no se precisa fecha alguna para este ejemplar fragmentario (Ver L. Resines, Francisco de Pareja. Doctrina cristiana muy útil y necesaria, México 1578, Salamanca, Servicio de Publicaciones de la Universidad, 1990, 37-39). En cambio, en la edición

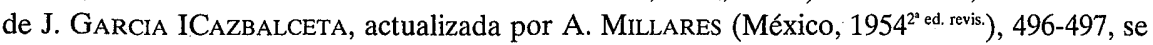
aventura la fecha situándola en la década de 1550-1560: “155...". La razón es simplemente la sospecha de que pudiera tratarse de la Doctrina de Motolinía, pero sin otro argumento mayor. A ello hay que añadir el desconocimiento de la edición de México, 1578.

12. L. REsines, o.c., 39.

13. Actualmente existente en la Public Library, de New York. 
to le faltan la primera y la última página, razón por la cual J. García Icazbalceta no pudo hacer una descripción más precisa, pero el resto, con algunas salvedades ${ }^{14}$, es el mismo texto que la Doctrina fechada con seguridad en 1578 (y consiguientemente, también es el mismo texto que la edición de 1576 , que incluye la versión otomí). La certeza de que se trata de una edición posterior, aun desconociendo la fecha, supone que frente a la pluralidad de catecismos editados por esas fechas en México, y que desmoronan el sueño de una unificación en torno a un mismo texto, se mantenía una cierta preferencia por este texto de catecismo que se edita al menos en tres ocasiones distintas con absoluta certeza: 1576, en la versión trilingüe que incluye el otomí, el náhuatl y el castellano; 1578, en la versión bilingüe náhuatl castellano, y otra fecha posterior, indeterminado, también en la versión náhuat-castellano. Quizá haya que limitar la fecha de esta edición hasta 1585, como máximo, pues reunido entonces el III Concilio Provincial Mexicano, convocado por Pedro Moya de Contreras, compusieron otro catecismo, esta vez con carácter oficial 15 .

Si sabemos de la existencia cierta de tres ediciones de este texto de catecismo respaldado por la autoridad de Pedro Moya, no parece que haya demasiadas dificultades en admitir que pudiera estar siendo editado con

14. Esta edición sin fecha, localizada en New York supone una composición íntegra de nuevas planchas, que aproximadamente contienen en cada página la misma materia que la edición de México, 1578. La letra del texto castellano en la edición de New York es de cuerpo ligeramente mayor, por lo que los espacios en blanco que quedan en la columna correspondiente son menores. Los enunciados "Pregunta" y "Respuesta", así como sus respectivas abreviaturas cambian constantemente en el texto castellano y en el náhuatl con relación a la edición de México, 1578. Las separaciones entre palabras en el texto náhuatl están más nítidas en la edición de New York, que en la edición de México, 1578. Existe una larga serie de variantes en el texto castellano que sería prolijo enumerar aquí, y de la que simplemente me limito a dejar constancia global. Igualmente, en el texto náhuatl también se producen numerosas variantes, que tienden a corregir errores gramaticales consignados en la edición de México, 1578. La edición de New York tiene todas sus hojas paginadas en el recto, cosa que no sucede en la edición de México, 1578. El encabezamiento de la página $15 \mathrm{r}$ en la edición de México, 1578 dice -a diferencia de las demás páginas- "MexicanA", mientras que en la edición de New York en esa página aparece como en todas las demás en forma de abreviatura "MeXI."

Pese a todas estas diferencias, que dejan patente que se trata de otra edición diferente, es incuestionablemente la misma obra. Yo había arriesgado la suposición de que se trataba de una edición posterior, a la vista de la descripción realizada por ICAZBALCETA. Ahora, con la reproducción del ejemplar fragmentario a la vista, puedo tener la certeza moral de que efectivamente se trata de una edición posterior, pese a que falta la última hoja, en la cual consta -al menos en la edición de México, 1578- la fecha de la impresión.

15. E. J. Burrus, The Author of the Mexican Council Catechism, en "The Americas" 15(1958) 171-182; L. REsines, Catecismos americanos del siglo XVI, Salamanca, Junta de Castilla y León, 1992. 
anterioridad a 1576 y que Pedro Moya ordenara a Melchor de Vargas que hiciera la versión a la lengua otomí para poderlo utilizar en la evangelización de los indios que hablaban aquel idioma. Las razones que he aducido para asignar la autoría de este texto a Francisco de Pareja siguen siendo perfectamente válidas, y desde el punto de vista cronológico no existe dificultad alguna en adelantar la fecha de composición. Francisco de Pareja llegó a México el 8 de mayo de 1569, y sólo en 1594 es enviado junto con otros 13 franciscanos a La Florida: en él período que media entre 1569 y 1576 (fecha de la edición trilingüe) pudo perfectamente publicar el catecismo en dos versiones que Melchor de Vargas se encarga de traducir, además, al otomí en $1576{ }^{16}$. Ahora, con nuevos datos, parece que la respuesta más lógica hay que buscarla en los siguientes términos: suponiendo la existencia de la Doctrina de Francisco de Pareja con anterioridad a 1576, de la que existe constancia de dos ejemplares, (uno fechado en 1578 y otro que carece de fecha, pero posiblemente posterior a 1578 y anterior a 1585), Pedro Moya determina en 1576 que se conserven las versiones náhuatl y castellana y, además, se enriquezca con la versión otomí, que encarga a Melchor de Vargas.

Queda aún un asunto por resolver: si existía anteriormente alguna edición de esta Doctrina, o si se edita por vez primera en 1576 en la doble presentación bilingüe y trilingüe que de hecho encontramos, ¿por qué seguir haciendo una edición bilingüe (castellano-náhuatl) si ya existía en 1576 una versión trilingüe (castellano-náhuatl-otomí) que cubría con creces las necesidades, pues el texto no cambia en absoluto (salvo leves correcciones)? La respuesta hay que buscarla en razones de índole económica. Aunque la edición de la Doctrina de 1576 está incompleta a partir de la página 27 (además de las páginas 24-26), el hecho de que contenga la misma exposición catequética en una disposición tipográfica invariable, permite hacer un cálculo exacto de las páginas que tendría que tener el ejemplar íntegro.

El contenido de esta edición de 1576 se interrumpe al comienzo de los sacramentos. La parte $4^{\text {a }}$ (la exposición de los sacramentos) ocupa en la edición de Francisco de Pareja de 1578: la segunda mitad del f.14r, los f. 14v, $15 \mathrm{r}-\mathrm{v}, 16 \mathrm{r}$ y la primera mitad del f. 16v, es decir, en total cinco páginas dispuestas en dos columnas que contienen el texto castellano y náhuatl. En la edición de 1576, con arreglo a la disposición del texto, la versión náhuatl

16. En L. Resines, Francisco de Pareja. Doctrina cristiana muy útil y necesaria.México, 1578, Salamanca, Servicio de Publicaciones de la Universidad, 1990, 26 afirmaba: "Hay que reçhazar que la orden de Pedro Moya respecto a la Doctrina de 1578 consista en la versión al náhuatl, puesto que la de 1576 de Melchor de Vargas es trilingüe (castellano-náhuatl-otomí): carece de lógica ordenar que se ejecute lo que ya está hecho y publicado". 
ocuparía 5 páginas completas que corresponderían a las páginas vueltas $27 \mathrm{v}$, $28 \mathrm{v}, 29 \mathrm{v}, 30 \mathrm{v}, \mathrm{y} 31 \mathrm{v}$ (pues va dispuesto a toda página); y el texto castellano y otomí, presentado en dos columnas de una misma páginas, ocuparía otras cinco páginas, que en este caso serían las páginas rectas $28 \mathrm{r}, 29 \mathrm{r}, 30 \mathrm{r}, 31 \mathrm{r}$, y $32 \mathrm{r}$. Con arreglo a este cálculo, quedaría disponible la página $32 \mathrm{v}$, que según anuncia el f. 2 r, contendría los "avisos para saber la lengua otomí", que "van a la postre en la vltima hoja deste libro".

Reconstruído de esta forma el contenido completo del libro, tenemos la versión trilingüe de 1576 con 32 hojas (en recto y vuelto). Este libro tendría que ser el doble de caro que la versión bilingüe de 1578, con sólo 16 hojas (en recto y vuelto). Lógicamente al resultar más barato, el libro gozaría de una mayor difusión manteniendo la versión bilingüe, además de la restrictiva y forzosamente más cara versión trilingüe, reducida a la zona de influencia de la lengua otomí; esta versión, no se abarata, de hecho, con la composición únicamente en castellano y otomí, por el hecho de que la lengua náhuatl era la de uso más generalizado, a partir de la cual los misioneros podrían empezar a llevar a cabo el acercamiento a los otomíes en su propia lengua; de hecho la lengua otomí se hablaba únicamente en la zona que se extiende al NE de México, capital, mientras la náhuatl era común en toda la región. Esto justifica perfectamente que se hagan dos variantes distintas del mismo catecismo. Y esto justifica igualmente que Melchor de Vargas se responsabiliza, con una encomiable honradez, únicamente de la versión que lleva a cabo al otomí, mientras que del contenido castellano de la obra y de la versión náhuatl se desentiende pues no han brotado de su pluma.

Respecto al contenido de esta Doctrina christiana y a su esquema catequético, así como la cuestión de la dependencia de otros catecismos, y el asombroso parecido con el catecismo de Gaspar Astete, que por esas mismas fechas sabemos documentalmente que su autor tenía ya compuesto y listo para la censura ${ }^{17}$, no hay nada nuevo que añadir que no conste ya en la edición facsímil de la Doctrina de 1578. El adelantar con seguridad la fecha de publicación en México un par de años, de 1578 a 1576, del mismo texto sigue reforzando la idea de que a uno y otro lado del Atlántico los misioneros empleaban para la evangelización del viejo pueblo cristiano o de los recién llegados a la fe los mismos esquemas procedimientos, preguntas y formularios, que eran repetidos con fijeza inexorable y que admitían cambios dentro de un patrón común del que todos participaban. 


\section{EL TRADUCTOR.}

Con tantas argumentaciones para tratar de situar el mismo texto de la Doctrina en las versiones que hoy conocemos gracias a los datos recientemente conseguidos, es posible llegar a olvidar al traductor del texto al otomí, Melchor de Vargas. Lamentablemente, desconozco ese idioma en absoluto, y por tanto no estoy en condiciones de poder señalar si su versión está bien o mal ejecutada, si es un lenguaje culto o burdo, si ha acertado o no a la hora de expresar conceptos acuñados en castellano y de los que carecía una lengua americana.

Por desgracia, el libro ahora consultado no añade ningún otro dato a los poquísimos que conocemos de él, y que me limito a reproducir aquí: "La penuria de datos se convierte en el caso de Melchor de Vargas en absoluta desolación, pues la carencia de noticias es casi absoluta. Icazbalceta aporta el principal -y por cierto bien escaso- dato biográfico: 'No he hallado otra mención que la de Grijalva (Edad II, cap. 18), en estos términos: "Envió (el provincial Fr. Juan Adriano, electo en 1590) por su fundador (del convento de Atlixco) al P. Fr. Melchor de Vargas, presentado, persona de muchas letras y autoridad, definidor y visitador de las nuevas constituciones en la provincia"'. Complementario del anterior, Vela aporta por su parte el siguiente: 'El P. Sicardo, en sus Adiciones, dice: En el Capítulo celebrado por la Provincia de México el 25 de abril de 1587 fue elegido Visitador el P. Presentado Fr. Melchor de Vargas'.

Si a tan escasa información añadimos el dato que proporciona la portada de su catecismo, sabemos de él con certeza que en 1576 es prior de Atocpán; en 1578 (el 25 de abril) es elegido visitador por la provincia de México, a la que pertenecía, sin duda; y en 1590, además de definidor y visitador, es enviado por el provincial como fundador del convento de Atlixco; por último, el conciso pero elocuente relato de sus cualidades morales. $\mathrm{Y}$ con esto concluye nuestra información sobre él" 18.

L. RESINES

18. L. Resines, Catecismos americanos de religiosos agustinos en el siglo XVI, en Varios, Agustinos en América y Filipinas. Actas del Congreso Internacional, ValladolidMadrid, 1990, 519. La referencia de ICAZBALCETA, consta en la obra varias veces citada, 277; la referencia de G. DE SAnTiago Vela, Ensayo de una Biblioteca Ibero-Americana de la Orden de San Agustín, VIII, 97. 